\title{
Medical Image of the Month: Chronic Ogilvie's Syndrome
}

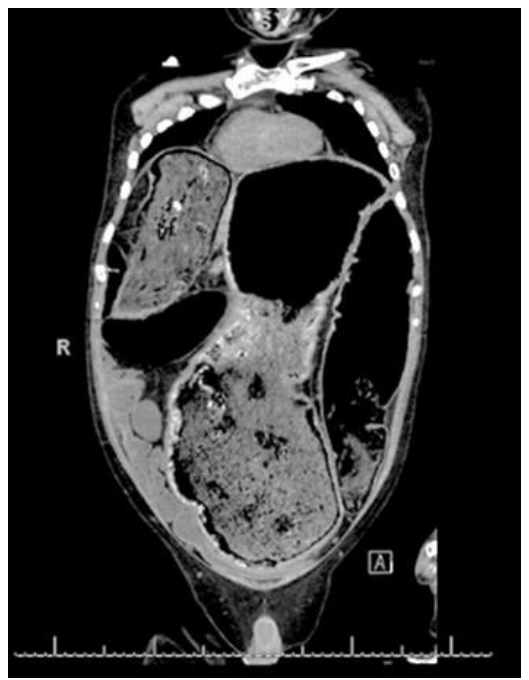

Figure 1. Coronal view of abdominal CT scan showing a massively dilated colon.

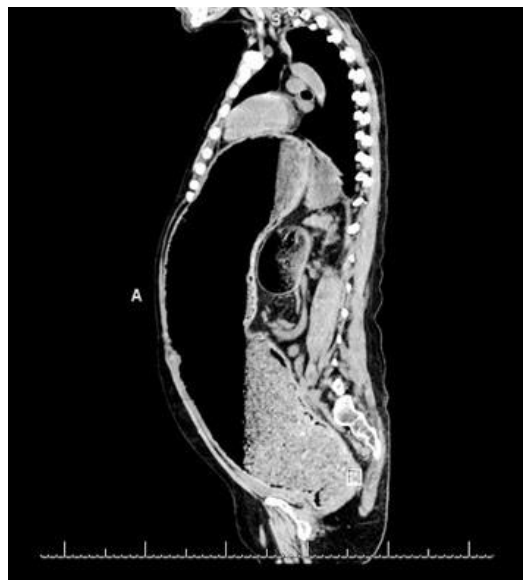

Figure 2. Sagittal view of abdominal CT scan.

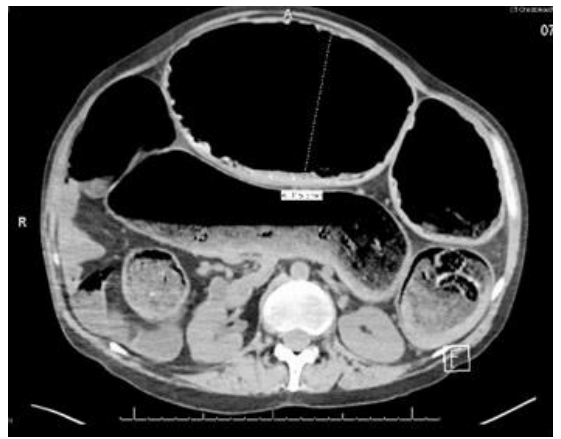

Figure 3. Axial view of abdominal CT scan. 
A 42-year-old man with chronic encephalopathy secondary to traumatic brain injury (TBI), craniotomy, seizure disorder, chronic alcohol abuse, and chronic Ogilvie syndrome presented to the Banner University Medical Center-South Campus emergency department (ED) after being found in his driveway with altered mental status. He complained of multiple episodes of non-bloody diarrhea for the last day but otherwise altered \& unhelpful. He was noted to have to be hypotensive with a blood pressure of $70-90 / 35-56 \mathrm{~mm} \mathrm{Hg}$, afebrile with a temperature of $36^{\circ} \mathrm{C}$, an elevated white cell count of $13.3 \times 10^{9} \mathrm{cells} / \mathrm{L}$, a hemoglobin of $4.4 \mathrm{~g} / \mathrm{dL}$, a creatinine of $2.6 \mathrm{mg} / \mathrm{dL}$, a $\mathrm{BUN}$ of $30 \mathrm{mg} / \mathrm{dL}$, and an elevated lactic acid to $5.4 \mathrm{mmol} / \mathrm{L}$. Physical exam showed a massively dilated tympanic abdomen. Resuscitation and broad-spectrum antibiotics were initiated, a CT scan ordered (Figures 1-3) and he was admitted to the medical intensive care unit (MICU) for further work up and management.

On chart review, it was shown that he had presented to the same ED twice in the past with episodes of chronic constipation. Gastroenterology and general surgery consults concluded that he had developed a chronic pseudo-obstruction pattern due to likely decreased gastrointestinal motility presumed secondary to TBI and immobility. He was evaluated and deemed to not qualify for neostigmine treatment due to finding of stool acting as a mechanical obstruction. During this MICU visit, he was treated for septic shock but unfortunately did not survive the hospital stay.

Learning Points/Take Home Message:

1. Ogilvie syndrome is an acquired dilation of the colon in the absence of any mechanical obstruction in severely ill patients characterized by abnormalities affecting the involuntary, rhythmic muscular contractions within the colon. The symptoms of Ogilvie syndrome mimic those of mechanical obstruction of the colon, but no physical obstruction is present.

2. Studies have shown that intravenous administration of neostigmine has led to rapid decompression of the colon in individuals with Ogilvie syndrome who did not respond to conservative management.

3. Colonoscopic decompression, in which a thin, flexible tube is inserted into the anal passage and threaded up to the colon, may be used in refractory cases. Although colonoscopic decompression has not undergone clinical study, numerous reports in the medical literature cite it as an effective method for removing air from the colon and, potentially, reducing the risk of perforation.

4. Surgery is used when affected individuals have signs of perforation or ischemia or have failed to respond to other treatment options. Surgery can be associated with significant morbidity and mortality.

Michael Bernaba MD, Emilio Power MD, Sidra Raoof MD, Babitha Bijin MD, Yuet-Ming Chan MD

Department of Internal Medicine

University of Arizona College of Medicine at South Campus

Tucson, AZ USA 


\section{References}

1. McNamara R, Mihalakis MJ. Acute colonic pseudo-obstruction: rapid correction with neostigmine in the emergency department. J Emerg Med. 2008;35:167-70. [CrossRef] [PubMed]

2. Saunders MD, Kimmey MB. Systemic review: acute colonic pseudo-obstruction. Aliment Pharmacol Ther. 2005;22:917-25. [CrossRef] [PubMed]

3. Maloney N, Vargas HD. Acute intestinal pseudo-obstruction (Ogilvie's syndrome). Clin Colon Rectal Surg. 2005;18:96-101. [CrossRef] [PubMed]

4. De Giorgio R, Knowles $\mathrm{CH}$. Acute colonic pseudo-obstruction. Br J Surg. 2009;96:229-39. [CrossRef] [PubMed] 